\title{
ECOPEDAGOGIA: CONTRIBUIÇÕES PARA PRÁTICAS PEDAGÓGICAS EM EDUCAÇÃO AMBIENTAL
}

Fábio Soares Guerra $1^{1}$

\section{RESUMO}

A Ecopedagogia surge como proposta pedagógica, no contexto da educação contemporânea, como fundamento possível para a Educação Ambiental. Trabalhada em conjunto com conceitos científicos já consolidados, a mesma poderá fornecer subsídios para a superação dos obstáculos impostos pela educação tradicional. Destarte, o presente estudo, tendo como recurso metodológico a análise documental e a pesquisa bibliográfica, materializa-se como ensaio teórico, buscando fazer reflexões acerca dos fundamentos epistemológicos disponíveis à Ecopedagogia para auxiliar a docência socioambiental.

Palavras-chave: Ecopedagogia. Educação Ambiental. Práticas Pedagógicas. Docência.

\section{ECOPEDAGOGY: CONTRIBUTIONS TO PEDAGOGICAL PRACTICES IN ENVIRONMENTAL EDUCATION}

\begin{abstract}
Ecopedagogia emerges as a pedagogical proposal, in the context of contemporary education, as a possible foundation for Environmental Education. Worked together with already consolidated scientific concepts, it can provide subsidies to overcome the obstacles imposed by traditional education. Thus, the present study, having as a methodological resource the documentary analysis and the bibliographical research, materializes as a theoretical essay, seeking to make reflections about the epistemological foundations available to the Ecopedagogia to assist socioenvironmental teaching.
\end{abstract}

Keywords: Ecopedagogy. Environmental Education. Pedagogical Practices. Teaching.

1 Especialista em Educação Ambiental - Universidade Estadual do Ceará - UECE. Graduado em Geografia. Professor da Rede Municipal de Ensino de Fortaleza -SME. E-mail: fabiosoaresguerra@hotmail.com. 


\section{INTRODUÇÃO}

A Educação Ambiental (EA) apresenta-se como uma gama de processos por meio dos quais somos levados a compreender as implicações das alterações humanas sobre o meio natural. Além disso, a mesma nos capacita a desenvolver valores, princípios e atitudes para a devida relação entre nós mesmos, com as demais formas de vida e os recursos naturais. Sendo assim, a EA ergue-se como uma condução ética para o melhoramento da qualidade do meio ambiente (GUERRA, 2017).

A EA encontra-se ainda na árdua elaboração de seus pressupostos epistemológicos, na busca por fundamentos que possam embasar a práxis de sua atuação como proposta docente. Nesse ínterim, intencionando a conjugação entre o ambiental e o social, esferas que constituem os objetivos traçados para a Educação Ambiental, destaca-se um conceito basilar para o auxílio na consolidação de uma educação voltada para as questões socioambientais, qual seja, a Ecopedagogia.

Por conseguinte, afirma-se que a proposta pedagógica da mesma está para além de "projetos de despoluição e/ou preservação, para vir a compreender uma vida sustentável. Ao mesmo tempo pretende ir além da escola e impregnar toda a sociedade, todos os ambientes, a começar pela conversão da subjetividade" (RUSCHEINSKY, 2002, p. 61).

Desta forma, a vertente ecopedagógica contribui como aporte significativo para a construção de uma consciência ecológica, de valores éticos, de atitudes salutares e uma reorientação de visão sobre o meio ambiente e educação, tanto a nível individual como coletivo. Nesse contexto, busca-se no presente ensaio ponderar e discutir acerca das correlações epistemológicas possíveis que podem embasar a Ecopedagogia como contributo à Educação Ambiental.

O presente estudo teve como procedimento metodológico a análise documental que "baseia-se em materiais que não receberam ainda um tratamento analítico ou que podem ser reelaborados de acordo com os objetivos da pesquisa" (PRODANOV; FREITAS, 2013, p. 55).

Além do que, recorreu-se a análise bibliográfica que, por sua vez, é "elaborada a partir de material já publicado, constituído principalmente de: 
livros, revistas, publicações em periódicos e artigos científicos, jornais, boletins, monografias, dissertações, teses, [...]" (Ibid., p. 54).

A abordagem qualitativa foi 0 norte orientador tomado para a investigação, considerando que "há uma relação dinâmica entre o mundo real e o sujeito, isto é, um vínculo indissociável entre o mundo objetivo e a subjetividade do sujeito que não pode ser traduzido em números" (op. cit., p. 70.).

\section{PERCEPÇÃO AMBIENTAL COMO INSTRUMENTO FORMATIVO}

O sistema político-econômico em curso tem como um dos arrimos principais a indústria moderna, isso pressupõe a exigência crescente de matéria-prima para manter a produção em ritmo diuturno. Consequentemente, os recursos naturais, isto é, a matéria-prima, que é a base da produção industrial, é extraída em demasia. Um exemplo disso é a Serra Pelada, localizada em Curionópolis, município do estado do Pará, região norte do Brasil.

Acreditava-se até então que no Brasil não havia mais grandes jazidas de ouro, contudo no início da década de 80 do século XX a grande jazida batizada de Serra Pelada, que a princípio era uma Serra e que depois de tanta extração foi transformada numa grande depressão chegando a atingir o lençol freático, foi explorada exaustivamente. Em função dessa grande descoberta, ocorreu um intenso movimento migratório para aquela região e cidades surgiram na circunvizinhança.

O exemplo acima comprova que a mentalidade social é que os recursos naturais são mercadorias que podem e devem ser exploradas e comercializadas a qualquer custo, independente das consequências. Mudar a visão sobre o meio ambiente, desenvolver a Percepção Ambiental é sem dúvida um dos motes da questão. Trabalhar com a EA significa, necessariamente, trabalhar com a cognição. Isso é tão certo quanto óbvio. Pois bem, a cognição vai se desdobrar em vários aspectos, a saber: a inteligência, a memória, a aprendizagem e, entre outros, a atividade perceptiva.

De acordo com Guerra (2017), a percepção é um meio pelo qual o indivíduo descobre e compreende a si mesmo, o mundo ao redor e as relações estabelecidas, capacitando-se como sujeito consciente. À vista disso, é 
possível falar em Percepção Ambiental. Com o desenvolvimento da Psicologia como ciência, esse ramo tomou corpo e forma, tornando-se campo de investigação científica embasando vários estudos voltados para a análise socioambiental.

Diante desse quadro, a pergunta crucial é: como percebemos o meio ambiente? Parece ser uma pergunta trivial, entretanto, não é. Visto que, a maneira como encara-se a natureza vai determinar a postura adotada para com ela. Um exemplo disso é o modelo econômico capitalista praticado, que visa o lucro a todo custo e encara os recursos naturais como produto a ser explorado e assim o faz de forma irracional, arquitetada, inconsequente.

Doravante, tendo uma visão/percepção ambientalista de mundo, reconheceremos os recursos naturais como componentes ambientais finitos. Desta maneira, os exploraremos, caso necessário, de forma racional, respeitando as potencialidades e os limites de cada recurso visando à Sustentabilidade. Portanto, a Percepção Ambiental é, de fato, imprescindível para a construção de uma Ecopedagogia. Desta feita, faz-se necessário entendê-la em seus pressupostos. No que tange a isso, concordamos que:

As variáveis fundamentais da percepção são espaciais e temporais, pois o nosso mundo tem extensão e duração. Percebe-se o que tem significado, pois a percepção é um mecanismo de defesa do EU (self) contra a insegurança e a ansiedade. A percepção de si mesmo e do mundo não é um evento isolado nem isolável da vida cotidiana das pessoas. Assim percebem-se não as formas, mas os objetos que tem significado. De inúmeros e múltiplos objetos selecionam-se, separamse, de algum ou alguns dos que mais chamam a atenção, isto é, o que mais tem significado para nós, para atender nossas necessidades e interesses (OLIVEIRA; MACHADO, 2010, p. 130).

Neste caso, conclui-se que a Percepção Ambiental deve ser uma das bases da Ecopedagogia que, por seu turno, auxiliará a Educação Ambiental em seu arcabouço teórico e prático a nível social e ambiental. É bem verdade que depois da Revolução Industrial, a humanidade chegou a um nível de desenvolvimento jamais visto. Não se pode negar, também, que isso beneficiou a muitos, porém, excluiu tantos outros mais dos benefícios do processo. Toda essa construção histórica foi dada à custa dos recursos ambientais. Concordase que:

O desenvolvimento econômico, por implicar uma intensificação da atividade econômica, acentua o processo de saque sobre a natureza e a devolução ao meio ambiente dos resíduos de fabricação ou 
utilização dos bens econômicos. Como consequência, há uma interação entre esses dois sistemas, ou seja, o sistema econômico e o sistema natural. Aquilo que se retira e aquilo que volta ao meio ambiente, por obra da atividade econômica, passa a ganhar relevância para ambos, não podendo mais ser ignorado. A ação de um deles sobre um deles tem de levar em conta, necessariamente, a repercussão que acarretará sobre o outro (OLIVEIRA; MACHADO, 2010, p. 137).

Esse ciclo acaba por degradar cada vez mais a natureza, destruindo os bens naturais ainda disponíveis, comprovando que toda proposta de desenvolvimento econômico do atual modelo compromete não só os recursos naturais, mas também a própria vida no planeta. Logo, esse ciclo deve ser contido. Caso contrário, o próprio suposto progresso pode ser inviabilizado. Por conseguinte, faz-se preciso uma reorientação educacional, aí entra a Educação Ambiental, subsidiada por uma maior percepção dos processos sociais e naturais, levando à construção de uma consciência ecopedagógica.

Entretanto, qual é a percepção majoritária acerca dos recursos ambientais? Infelizmente, a estrutura daquilo que compreendemos como civilização torna-se por demais complexa, dia a dia, transformando o mundo natural em um mundo manufaturado. Isso distancia a sociedade de suas raízes, o mundo deixa de ser predominantemente rural para ser um mundo urbano, fragilizando e distanciando o contato com a natureza, com a terra. Como consequência, o modo de vida citadino acaba por subordinar a cultura, os valores e os saberes historicamente elaborados e reelaborados pelo campesinato.

Tendo a Percepção Ambiental como um dos fundamentos da Ecopedagogia auxiliando a EA, a realidade posta pode ser questionada, contra argumentada e transformada por tomadas de decisões apropriadas a cada caso, mudando assim a percepção reinante de civilização, de sociedade, de consumo e, sobretudo, o valor do meio ambiente.

\section{VULNERABILIDADE SOCIOAMBIENTAL COMO TEMÁTICA DE ENSINO}

Outro conceito a ser apreendido pela Ecopedagogia, por meio da Percepção Ambiental é o de Vulnerabilidade Socioambiental. Uma das peças chaves para a superação dos entraves didáticos e metodológicos da EA.

A vulnerabilidade é uma noção multidimensional, à medida que afeta indivíduos, grupos e comunidade em planos distintos de seu bem- 
estar, de diferentes formas e intensidade. A vulnerabilidade social de pessoas, famílias ou comunidade são entendidas como uma combinação de fatores que possam produzir uma deterioração de seu nível de bem-estar, em consequência de sua exposição a determinados tipos de riscos (COSTA, 2009, p. 145).

Assim, pode-se concluir que:

A desigualdade de acesso às condições urbanas de vida se expressa também como desigualdade ambiental, pois as populações com menor poder aquisitivo tendem a localizarem-se nas chamadas áreas de risco, ou seja, áreas de maior exposição a situações insalubres (contaminação de água, do solo, e do ar) e inseguras (riscos de acidentes de diversos tipos) (Ibid. p.147).

Diante do exposto, a questão da Vulnerabilidade faz-se nítida e, portanto, apreensível por meio de metodologia adequada, ou seja, por meio da percepção dos riscos ambientais, fundamentando a Ecopedagogia que, por sua vez, subsidia a Educação Ambiental. Na capital cearense, Fortaleza, cidade de espacialização radioconcêntrica e excludente, há inúmeras localidades que podem abrir um leque de possibilidades de análise sob esse viés, principalmente os bairros da parte oeste da capital que na maioria dos casos apresentam crescimento espontâneo e marginal.

Vamos tomar como base o Conjunto Ceará, bairro do subúrbio fortalezense. O Conjunto Ceará é o maior conjunto habitacional da cidade. Abriga população, comércio e uma gama de serviços bem significativos. Construído nos anos 1970 pela COHAB-CE sob o princípio urbanístico de unidade de vizinhança, portanto, a priori um bairro residencial que na construção e reconstrução constante de seu espaço tomou outros contornos e múltiplas funcionalidades. É drenado por uma série de córregos e transpassado por inúmeras vias principais e coletoras de trânsito. Nesses locais agregam-se alguns problemas.

Os córregos foram, quase na totalidade, canalizados. Neles são despejados o esgoto sanitário do bairro, conjugados a outros poluentes os mesmos formam um verdadeiro esgoto a céu aberto. O odor, as doenças epidérmicas e respiratórias, os transbordamentos, entre tantos problemas resultantes, configuram a paisagem do local. 
Figura 1- Bairro Conjunto Ceará, subúrbio de Fortaleza-CE.
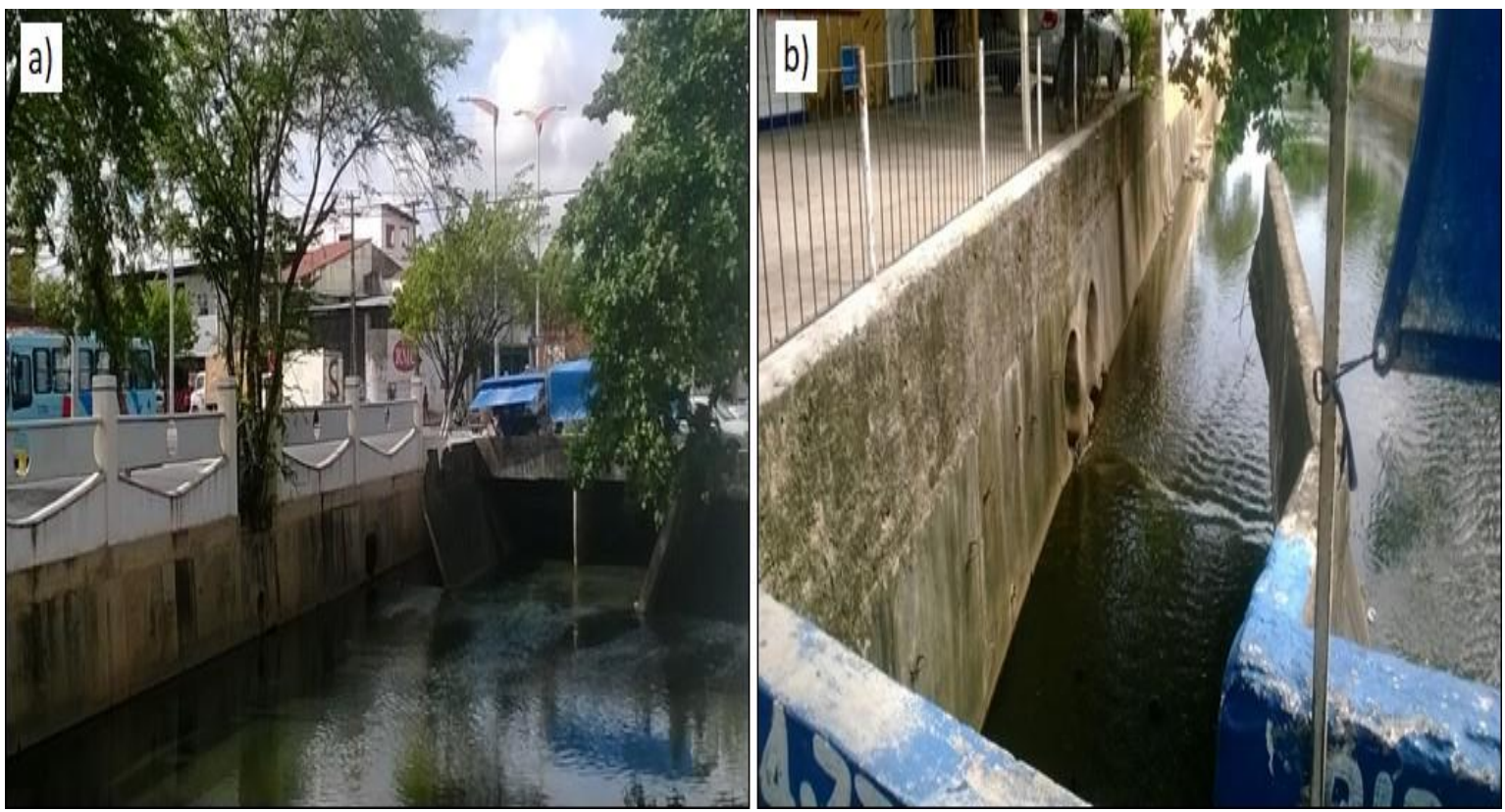

Fonte: suprimida para avaliação às cegas.

Na Figura 1a é observado um dos canais mencionados, é o canal da Av. C que separa a $4^{a}$ da $2^{a}$ etapa do Conjunto Ceará, detalhe: as etapas não seguem uma sequência crescente. Nota-se que nas paredes do canal há saídas de bueiros que dejetam no próprio canal. A Figura 1b, demonstra como acontece.

Diante tal cenário, subsidiados pela Percepção Ambiental e o conceito de Vulnerabilidade Socioambiental, indagamos: qual é a mentalidade dos gestores públicos no que diz respeito à gestão e o planejamento ambiental, ao meio ambiente, à noção de cidade adequada? A população, por sua vez, assimila e internaliza as mesmas ideias como consequência daquilo que ela vivencia cotidianamente. Desta forma, a precarização socioambiental é naturalizada, essa realidade orienta as representações sociais que são construídas sobre a natureza, por consequência, conduz as atitudes tomadas para com ela.

Além do que, tal quadro socioambiental gera todo 0 tipo de vulnerabilidade quanto à saúde, segurança e moradia. Estabelecendo-se, entrementes, zonas de topofobias. Nesse ensejo, imaginemos a qualidade de vida dos que moram às margens desse canal! 
Figura 2 - Conjunto Ceará, 4ª etapa, próximo ao município de Caucaia-CE.

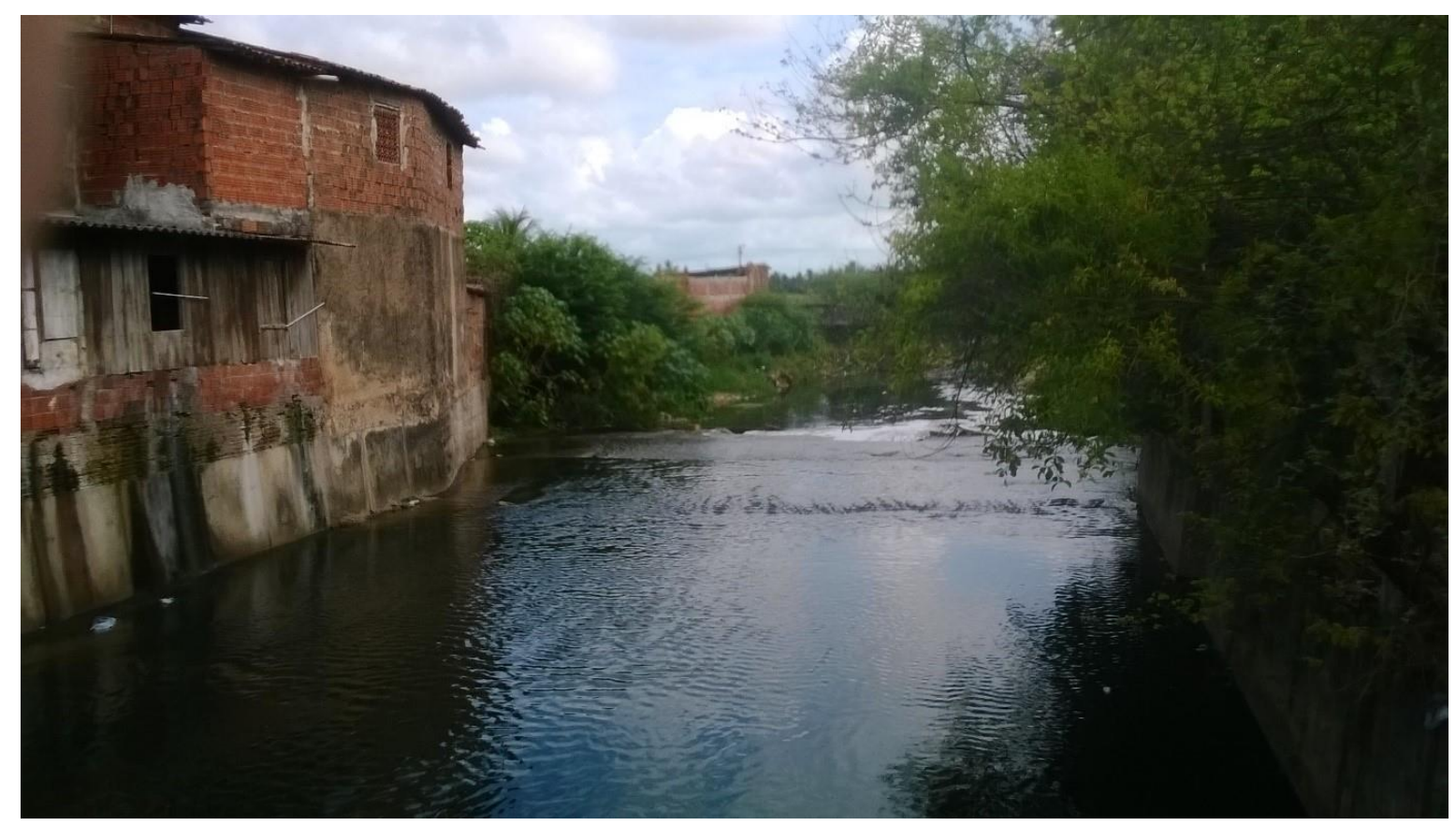

Fonte: suprimida para avaliação às cegas.

Diante do cenário apresentado na Figura 2 é perceptível o total despreparo dos gestores públicos que não são capazes de entender que "a cidade como ecossistema deverá ser configurada por suas relações com o entorno e com os recursos naturais locais, especialmente a água, a energia, as matérias-primas para os materiais de construção e os alimentos" (RIBEIRO, 2000 , p. 57). Além disso, evidencia-se a mentalidade meramente utilitarista que acaba por se impregnar no imaginário social agravando o problema relativo à atual e incompatível relação sociedade e natureza. Campo extenso, então, para a realização de práticas educativas (formais ou informais) com Educação Ambiental.

Entretanto, diante do que foi exposto até então, torna-se explicita a necessidade de elaboração e difusão de uma nova ética, de novos valores para o meio ambiente por meio da Ecopedagogia. É inegável a existência de uma possível conexão entre valores ético, meio ambiente e educação. Esse fato não é de interesse do discurso capitalista, por razões mais do que óbvias. Diante disso, cabe a Ecopedagogia embasar as conexões entre os fatores destacados.

Para tanto, o discurso intelectual sozinho não será capaz de concretizar as conexões propostas. É preciso mais do que retórica e bibliografia. A 
conjugação entre academia, sociedade civil organizada e interesse político é de suma importância para se definir o tipo de EA que a sociedade deseja e necessita. Educação Ambiental voltada para quais interesses, para a construção de quais valores, de quais princípios, para que tipo de sociedade? São reflexões indispensáveis para superarmos os entraves e os paradigmas da educação tradicional, calcada em interesses puramente econômico, além de seus próprios paradigmas didático-metodológico emperrantes, atrasados, com sua forma de educação que nega ou relega a práxis para desenvolver uma Pedagogia meramente simplória e memorística (FREIRE, 1987).

Sendo assim, a Ecopedagogia vem como contraponto, como proposta de educação consistente, disseminando e propondo o diálogo democrático e permanente entre o ambiente construído e o espaço subjetivo (simbólico), tendo a natureza como ambiente conjugada à ação antrópica. Essa proposta de abordagem dialógica enriquece o discurso sobre o meio ambiente e o tratamento que lhe é dispensado.

Desta maneira, não se pode esquecer a participação dos atores sociais na construção do devir, dando e ao mesmo tempo renegando significados às relações sociais e 0 modo de perceber 0 ambiente, construindo e desconstruindo o meio que nos cerca. Nesse cenário, concebe-se a Ecopedagogia como um novo movimento pedagógico, que além de apontar e fomentar subsídios para a EA dissemina a necessidade de uma consciência ambiental coletiva para a transformação cultural e, sobretudo, de mentalidade para a atual geração tendenciada ao consumo, muitas vezes, sem a devida orientação acerca de princípios e referenciais.

\section{Desenvolvimento Sustentável para práticas ecopedagógicas}

É propósito da Ecopedagogia substantificar trabalhos visando a coletividade, de modo a consolidar os nexos com o Desenvolvimento Sustentável, que pode ser compreendido como "o desenvolvimento a partir de uma lógica que satisfaça as necessidades do presente, do nosso tempo vivido, sem comprometer a capacidade de satisfazer as necessidades das gerações futuras, de nossos filhos, netos, etc." (ROOS; BECKER, 2012, pg. 864).

Não obstante, essa é uma tarefa bastante laboriosa, por isso: 


\begin{abstract}
A Ecopedagogia visa à consolidação de uma consciência ecológica ampla, profunda e difusa. Para tanto, há de se investir em mudanças culturais que afetam a mentalidade, o comportamento como modo de pensar e agir, a cultura política, a visão de mundo, as representações sociais, a solidariedade e a participação. É a tentativa de desenhar e arquitetar a adoção de pontos de vista, de práticas e de movimentos sociais, assim como projetos políticos que deem conta dos dilemas ambientais da atualidade (RUSCHEINSKY, 2002, p. 67).
\end{abstract}

Assim, a Ecopedagogia para trabalhar as ideias da Sustentabilidade (Desenvolvimento Sustentável), conforme a citação acima, terá que buscar uma abordagem tanto multi quanto transdisciplinar para comtemplar todos os objetivos supracitados. De fato, algo bastante laborioso em vista das dimensões a serem abarcadas na intrínseca relação natureza e sociedade.

Para Gadotti (2009, p. 14), a Sustentabilidade é [...] "o sonho de bem viver; sustentabilidade é equilíbrio dinâmico com o outro e com o meio ambiente, é harmonia entre os diferentes". Sendo assim, a Sustentabilidade tem que ser vista como um conceito a ser trabalhado em todas as dimensões da educação. Um conceito sólido, baseado em premissas rigorosas.

A Sustentabilidade não tem por intuito anular o crescimento econômico e tecnológico. Muito pelo contrário, seu objetivo é orientar o crescimento econômico de modo a preservar os recursos naturais para as gerações futuras, para a manutenção da própria existência humana. O pensamento sustentável é, por demais, importante diante da crise ambiental vivenciada. As evidências dessa crise são tão nítidas que a temática é debatida por toda sociedade, quer por especialistas ou leigos, o meio ambiente é a temática do momento.

Posto que o alarmante grau de degradação, por consequência, tem impactado negativamente na vida de todos, seja na esfera da saúde pública, economia formal ou informal, segurança, moradia, em síntese a qualidade de tudo isso depende da qualidade ambiental, pelo menos até certo ponto. Isso por si justifica maiores ponderações sobre o conceito de Desenvolvimento Sustentável, acerca disso:

É possível enunciar a existência de duas grandes tendências no campo do desenvolvimento sustentável. A primeira volta-se para a proposição de soluções que se coadunam com a necessidade de preservação da biodiversidade, conservação dos recursos naturais, desenvolvimento local e diminuição das desigualdades sociais, por meio de novas tecnologias, políticas compensatórias, tratados internacionais de cooperação e de compromissos multilaterais, estímulo ao ecoturismo, certificação verde de mercadorias alternativas, entre outras. A segunda volta-se para finalidades 
semelhantes, mas por intermédio da inclusão social, na participação na tomada de decisões e da promoção de mudanças culturais nos padrões de felicidade e desenvolvimento. (SORRENTINO, 2011, p. 23).

Todavia, esse conceito, que em essência é pedagógico, não é compatível com o modelo econômico existente. São ambos necessariamente excludentes. Desta maneira, é preciso buscar outra orientação econômica para que o Desenvolvimento Sustentável promova relações sociais de produção menos predatórias e mais solidárias.

O processo educacional é de fundamental importância nesse projeto de mudança de concepções e ações, isso porque o processo pedagógico em si é dotado de intencionalidade. Por esse e outros motivos, cabe aos meios educativos, formais e informais, tecer as implicações do atual modo de vida, as premissas do modelo de produção em curso. Visando, dessa maneira, a exposição e os motivos da atual crise ambiental que trouxe fatídicas consequências para a natureza e a sociedade.

O conceito de Desenvolvimento Sustentável comporta em si uma faceta essencialmente educativa, isso se torna claro a base de qualquer análise crítica do referido conceito. A preservação ambiental depende de uma consciência ecológica e a construção de tal consciência necessita, indubitavelmente, de um processo educativo intencionalmente crítico e voltado para esses ditames.

Os objetivos da Ecopedagogia se confundem justamente com essa intencionalidade pedagógica. Ora, a relação homem e natureza acontece no nível do palpável ou sensibilidade, bem como ao nível do subconsciente. Para tanto, é preciso uma ecoformação para levar as variantes da complexa relação sociedade e meio ambiente à tona e provocar uma transformação. Para subsidiar essa ecoformação devemos admitir que:

Precisamos de uma ecopedagogia e de uma ecoformação hoje, precisamos de uma Pedagogia da Terra, justamente porque sem essa ecopedagogia para a 're-educação' do homem/mulher, principalmente do homem ocidental, prisioneiro de uma cultura cristão predatória, não podemos mais falar da terra como um lar, como uma toca para o "bicho homem" como dizia Paulo Freire. Sem uma educação para a vida sustentável, a Terra continuará sendo considerada como espaço do nosso sustento e de nosso domínio técnico-tecnológico, um ser para ser dominado, objetos de nossas pesquisas, ensaios e, algumas vezes, de nossa contemplação (GADOTTI, 2009, p. 63). 
A educação para o Desenvolvimento Sustentável intenciona de sobremaneira essa reeducação socioambiental. Propondo uma mudança de visão para com os recursos naturais. A Ecopedagogia em seus pilares a cada dia prepara-se para isso, segundo os trabalhos que vão sendo desenvolvidos, e isso vem acontecendo revestindo-a como um movimento pedagógico e de grande relevância na abordagem curricular.

Ademais, devemos ter o devido cuidado no trato e entendimento desse conceito. Pelo fato dele não ter apenas preceitos de cunho pedagógico. Como conceito recente, que ainda traça seus contornos, pode acabar tomando variadas direções. A Ecopedagogia pode ser levada pelo viés antiecológico conformatando-se como movimento social e político meramente. Algo a se ter cuidado. No entanto, como uma reeducação sócio-econômico-ambiental, a Ecopedagogia precisamente supõe uma reorientação em nível de currículo, traçando diretrizes para os conteúdos de relevância e a produção dos livros e materiais didáticos voltados aos interesses e a realidade do aluno.

De tal maneira, ela encaminha-se para a consolidação de um projeto bem mais amplo, concretiza-se como uma proposta alternativa e não como uma Pedagogia a mais simplesmente. Essa nova proposta está preocupada com a transformação do atual modelo de civilização e não com a simples conservação dos ecossistemas, redução dos impactos ambientais, recuperação de áreas degradadas, etc. A Ecopedagogia vai além, procurando viabilizar uma transformação nas estruturas de todo o sistema: nas esferas sociais, culturais e econômicas.

Doravante, é preciso fazer aqui uma cuidadosa distinção: educação sobre o Desenvolvimento Sustentável de educação para o Desenvolvimento Sustentável. A educação sobre o Desenvolvimento Sustentável tem a ver com a tomada de consciência, o debate teórico, a informação e os dados relativos ao crescimento com responsabilidade; já a educação para o Desenvolvimento Sustentável tem de ir para além da teoria, é usar a educação para construir um futuro mais digno, sustentável. Por isso, o exemplo de vida sustentável é indispensável. Trata-se mais do que um conjunto de conhecimento, é a aprendizagem e aplicação de atitudes éticas e coerentes, valores sociais, econômicos e ambientais. É motivar para a mudança, para a transformação de mentalidade e o trato com a natureza (GADOTTI, 2009). 


\section{PENSAMENTO SISTÊMICO PARA A DOCÊNCIA AMBIENTAL}

Não obstante, pode-se recorrer à Visão Sistêmica como contributo ecopedagógico explanando, correlacionando e debatendo os velhos paradigmas e as novas perspectivas de educação. De acordo com Capra (1994), é preciso perceber o surgimento da Visão Sistêmica, ou do Pensamento Sistêmico, como fruto das revoluções em vários campos: científico, técnico, político e cultural.

Isso, por conseguinte, envolverá uma mudança de percepção dos fenômenos e recursos naturais, a implementação de aparatos tecnológicos e a administração dos conflitos sociais. Surgindo, então, com uma nova propositura que é a de tecer um novo arcabouço intelectual que procura descrever a complexidade organizada, tendo em vista suas interações em redes dinâmicas, fundamentando-se no conceito de sistema (CAPRA, 1994).

"Assim, a relação todo-partes é reconsiderada; o conhecimento das partes só é possível pelo conhecimento do todo, que só é possível ser conhecido pelo conhecimento das partes. Complexidade é união da simplicidade e da totalidade" (TORZONI-REIS, 2004, p. 123). Na conjunção dessa tendência, o Pensamento Sistêmico objetiva compreender um fenômeno dentro de seu contexto em busca do todo das relações em oposição a mera soma das partes, ou seja, o estudo isolado das partes constituintes do fenômeno em estudo, de caráter fragmentário e simplista.

No entanto, é possível observar a existência de inúmeros tipos e variados níveis de complexidade que podem ser inseridos no conceito de sistema. Desta maneira, pressupomos, também, a existência de uma hierarquia entre as partes correlacionadas de uma mesma situação ou objeto de estudo. Tudo isso deve ser levado em conta nas práticas de ensino, visto que se trata de uma "nova visão da realidade, de que vimos falando", realidade essa fundamentada "na consciência do estado de inter-relação e interdependência essencial de todos os fenômenos - físicos, biológicos, psicológicos, sociais e culturais". (CAPRA, 1994, p.177).

Sobretudo, o Pensamento Sistêmico brota como ferramenta para analisar, compreender e explicar a complexidade das organizações sociais que trazem consigo problemas de toda magnitude. Problemas sociais, econômicos, 
políticos, culturais, ambientais, enfim. Problemas esses que vêm acarretar grande maleficidade sobre o meio ambiente. Portanto, na busca de seus pressupostos epistemológicos a Educação Ambiental pode se fazer valer do Pensamento Sistêmico como um referencial teórico a contribuir, na medida em que leva em conta o todo das interações. Isso ocorre por sua capacidade de analisar o meio em si, em sua totalidade, e a ação antrópica sobre o mesmo nos mais variados prismas, podendo estabelecer relações e correlações de diversas maneiras, entre múltiplos fatores, sejam elas sociais ou ambientais. Isto quebra com o paradigma da fragmentação científica tradicional que consubstancia a educação conservadora.

A educação tradicional engessou o raciocínio crítico-reflexivo e não assinala postura consciente e ativa para tomada de decisões, ao contrário postula e imprime uma Pedagogia bancária de cunho depositário, à mercê da práxis. Concepção inversa aos postulados do Pensamento Sistêmico. À vista disso, o professor figura como dono do conhecimento, o aluno uma caixa vazia a ser preenchida. A esse respeito, Paulo Freire menciona assertivamente:

Em lugar de comunicar-se, o educador faz 'comunicados' e depósitos que os educandos, meras incidências, recebem pacientemente, memorizam e repetem. Eis a concepção 'bancária' da educação, em que a única margem de ação que se oferece aos educandos é a de receberem os depósitos, guardá-los e arquivá-los. Margem para serem colecionadores ou fichadores das coisas que arquivam. No fundo, porém, os grandes arquivados são os homens, nesta (na melhor das hipóteses) equivocada concepção 'bancária' da educação (FREIRE, 1987, p.33).

Para reforçar o acima citado basta averiguar a etimologia da palavra professor e aluno. Aluno significa um ser sem luz. Professor é aquele que professa, nesse caso o conhecimento, sendo ele o dono do mesmo. E o pior, transmitindo-o de maneira compartimentada sem nenhuma conexão sistêmica com as demais disciplinas, entre seus próprios elementos constituintes e, sobretudo, a realidade do aluno que traz consigo uma gama de conhecimentos acumulados ao longo de sua experiência de vida. Desta feita, não há como o discente capturar o sentido e a importância do saber escolar, pois não vê nele nenhuma aplicabilidade, nenhum sentido prático, não conseguindo enxergar o feedback que o saber pode proporcionar à vida a médio ou a longo prazo em termos de crescimento pessoal, profissional, cultural, enfim. 


\section{POR UMA ECOFORMAÇÃO DIALÓGICA}

Tendo em vista a persistência da educação bancária nos mais variados sistemas de ensino, torna-se necessário encaminhar uma linha educacional mais dialógica (FREIRE, 1987). Nesse ínterim, o professor João Batista de Albuquerque Figueiredo assinala para um prisma analítico diferenciado para a Educação Ambiental: a perspectiva Eco-relacional (PER).

[...] procedendo a uma ruptura paradigmática, considerando a dimensão ambiental constituída também pelas esferas históricopolítica e sócio-cultural, nos permitimos, então, constituir o que denominamos de 'ecopráxis'. No adensamento dessa ruptura, avançamos no sentido da 'perspectiva eco-relacional' (FIGUEIREDO, 2003, p. 44).

Assim, o estudo socioambiental é inserido no contexto histórico, levando em conta o todo das relações que entremeiam os aspectos sociais, políticos e econômicos que constituem a realidade imposta marcada pela atual crise ambiental. Isso viabiliza a "ecopráxis" como ferramenta de transformação social. Corroborando com esse raciocínio:

\footnotetext{
O eco-relacional retrata o interativo de 'tudo com tudo' e toda a totalidade. $\mathrm{Na}$ verdade é uma proposta que representa a compreensão do Universo, na qual as totalidades são parcelas entremeadas, inseridas em totalidades ainda maiores, estruturando, desde o nível mais simples ao mais complexo, uma ligação de interdependência em busca da contínua eco-evolução (Ibid. p. 45).
}

A afirmativa acima mencionada apresenta-se oportuna no sentido de avançar na óptica analítica no que tange a complexidade da ambiência educacional, posto que focaliza não na singularidade dos fatores e sim no todo relacionado. Concepção diretamente proporcional ao Pensamento Sistêmico. Um representativo avanço epistemológico: uma base sólida para trabalhos didáticos e metodológicos no contexto ecopedagógico, como aporte à EA.

Com a revolução tecnológica, sobretudo, das últimas décadas, a forma tradicional do fazer pedagógico não satisfaz os novos anseios estabelecidos pela sociedade. Mais um motivo para se buscar novos caminhos para uma superação é apostar na ecoformação dialógica como uma das possíveis alternativas para fundamentação epistêmica buscada pela Educação Ambiental por uma tendência relacional. Nesse bojo, em relação à Modernidade, concluise que: 
Ser moderno é encontrar-se em um ambiente que promete aventura, poder, alegria, crescimento e autotransformação das coisas em redor - mas ao mesmo tempo ameaça destruir tudo que temos, tudo que sabemos, tudo que somos. A experiência ambiental da modernidade anula todas as fronteiras geográficas e raciais, de classe e nacionalidade, de religião e ideologia: nesse sentido pode-se dizer que a modernidade une a espécie humana. Porém, é uma unidade paradoxal, uma unidade de desunidade: ela nos despeja todos num turbilhão de permanente desintegração e mudança, de luta e contradição de ambiguidade e angústia. Ser moderno é fazer parte de um universo no qual, como disse Marx, 'tudo o que é sólido desmancha no ar' (BERGMAN, 1990, p. 15).

Isso evidencia a dificuldade do fazer pedagógico atual, posto que a realidade se torna cada vez mais efêmera diante de uma sociedade extremamente complexa e desigual. Além do mais, o atual sistema de produção mantém um ritmo de consumo sempre acelerado mudando a concepção social do que é realmente importante para uma vida digna. $E$ as perspectivas pioram, na medida em que é analisado mais a fundo os trâmites constitutivos da Modernidade:

\begin{abstract}
Se a vida moderna está de fato tão permeada pelo sentido do fugidio, do efêmero, do fragmentário e do contingente, há algumas profundas consequências. Para começar a modernidade não pode respeitar sequer o seu próprio passado, para não falar de qualquer ordem social pré-moderna. A transitoriedade das coisas dificulta a preservação de todo sentido de continuidade histórica. Se há algum sentido na história, há que se descobri-lo e defini-lo a partir de dentro do turbilhão da mudança, um turbilhão que afeta tanto os termos da discussão como o que está sendo discutido (HARVEY, 1989, p. 22).
\end{abstract}

Em vista disso, a sensação avassaladora do não apreensível, do não delimitável tem grandes repercussões nos desdobramentos da Pedagogia Tradicional. Ocorre entre docentes e discentes um verdadeiro choque de gerações. Os referenciais, os valores, as ideologias, o comportamento estético e até mesmo sexual entre ambos se mostram absurdamente díspares.

Isso resulta, necessariamente, em um entrave educacional: a falta de dialogicidade. Aprendizagem e rendimento caem, pois se criou uma barreira pedagógica. Diálogo, falta-lhe espaço necessário em sala de aula. Isso ocorre por quais motivos? Porque o currículo escolar não o engloba? É por que o mesmo não tem relevância social? É justamente o contrário de tudo isso que leva a perspectiva dialógica ter pouco espaço na escola básica e a até mesmo no espaço acadêmico, o fato dela trazer à superfície os pressupostos do imediatismo moderno que fincado numa racionalidade do novo, do lucro, transforma os recursos naturais em mercadorias a serem exploradas para se 
manter um insustentável modelo de vida. Então, a Educação Ambiental numa perspectiva eco-relacional tem por objetivo levar à consciência os aspectos da realidade imposta, assim a mesma ganha pouca ou nenhuma relevância dependendo dos gestores governamentais e educacionais.

Eco-relacionando meio ambiente, economia e educação, constata-se um projeto de globalização capitalista que se une ideologicamente com a proposta da Modernidade e desde os anos 70 do século XX, já se falando em PósModernidade, acentua ainda mais os problemas ecológicos, econômicos, políticos, culturais e pedagógicos do movimento anterior. Projeto esse puramente excludente e de grande prejuízo em termos social e ambiental.

De acordo com Eliseu S. Sposito (2004, p.135) a globalização pode ser entendida como uma "[...] tendência na homogeneização de usos e costumes, com a predominância de meios de comunicação que podem inibir qualquer reação ou crítica individualizada [...]". Carlos F. B. Loureiro (2011, p. 80) revelava uma das facetas da globalização quando afirma que a mesma é "[...] um fenômeno contraditório tipicamente moderno. Por um lado, é a expressão do desenvolvimento do capitalismo sem fronteiras (capitalismo financeiro e transnacional) que acentua as desigualdades; [...]".

Apenas por meio de práticas de ensino que contemple a dialogicidade eco-relacional entre educador e educando será possível promover a aprendizagem acerca da intenção do capital globalizado de homogeneizar as diferentes sociedades criando padrões de produção, comportamento e consumo. Tudo isso em função de um lucro exacerbado, que não respeita a instituição familiar, hábitos criados e repassados milenarmente, subordina 0 campo a um modo de vida urbano, invertendo a visão social de que o homem é parte da natureza e a manutenção da mesma é preciso para nossa própria sobrevivência, para representá-la como produto a ser subtraído.

No atual sistema econômico, político e ideológico o que observamos, na verdade, é uma autocracia da informação e do dinheiro, a nível mundial, o que acaba por reforçar a exclusão dos que estão à margem das vias de acesso e o ciclo vicioso da pobreza.

Entre os fatores constitutivos da globalização, em seu caráter perverso atual, encontram-se a forma como a informação é oferecida à humanidade e a emergência do dinheiro em estado puro como motor da vida econômica e social. São duas violências centrais, 
alicerces do sistema ideológico que justificam as ações hegemônicas e leva ao império das fabulações, a percepção fragmentada e ao discurso único do mundo, base dos novos totalitarismos - isto é, dos globalitarismos - a que estamos assistindo (SANTOS, 2008, p. 38).

A informação ao contrário de ampliar o conhecimento acerca do planeta, em função das novas condições técnicas, tem exercido um papel opressor, visto que é utilizada por um pequeno grupo que a manipula segundo seus próprios interesses, não esclarecendo e sim confundindo. Por isso, podemos dizer que ela é um resultado, um produto intencionalizado, uma ideologia. Pior de tudo: na visão do homem indouto, o real e a realidade se confundem, a verdade e a ideologia se conjugam, buscando instruir e convencer por meio da publicidade. Por resultado, percebemos uma sociedade com visão anuviada.

A base tecnológica de geração e divulgação da informação é propriedade de poucos países e de um número pequeno de empresas, isso por sua vez gera um abismo socioeconômico entre as nações ricas e pobres. Assim, a periferia do sistema entra em desvantagem, aprofundando a sua posição periférica a cada momento, por não possuir os meios de produção avançados e, desta forma, não conseguir a ascensão social.

Da mesma maneira que a informação, o capital financeiro se internacionalizou. Nessa nova lógica o esforço econômico passa a ser multinacional. Então, o dinheiro de uma empresa estrangeira com filiais na periferia do sistema, vai voltar para o país de origem maximizado. Enquanto isso os países periféricos oferecem incentivos fiscais e mão de obra barata, orientando todo o aparato de infraestrutura para a instalação das mesmas. 0 retorno financeiro para o país periférico, quando comparado com o valor expatriado, é irrisório.

O capitalismo transformou a lógica do trabalho humano, que a princípio visava à subsistência ou, em alguns casos, a formas primitivas de comércio que visava o sustento familiar e não o acúmulo de excedentes. Com o comércio em larga escala, fundamentado nos funestos princípios capitalistas e a injusta apropriação dos meios de produção pela minoria, os proletários ficam tanto alienados em relação ao processo produtivo bem como em relação ao fruto do seu próprio trabalho.

Essa situação tem criado representações sociais completamente alienantes por meio dos comerciais, do marketing, da televisão, da arte, do 
cinema, da música, etc. O mundo torna-se o mundo do consumo, da obsolescência programada, das vitrines, do fast-food. Vivia-se o mundo natural, o campo era o centro da vida humana, passa-se a viver um mundo industrial e urbano que subordina o rural, agora vivencia-se o capitalismo financeiro que inviabiliza o crescimento da periferia.

Por resultado, os sistemas educacionais são voltados para justificar e reforçar os ditames da realidade imposta pelo sistema social de produção praticado, de modo a se manter a dicotomia centro e periferia. Diante disso, os educandos passam a ser formados segundo o perfil esperado de cidadão, dentro da seguinte lógica: os que pensam, os que executam e os que consomem. A Educação Ambiental, nesse contexto, acaba se tornando "um tipo de instrução de caráter essencialmente técnico, que mais se assemelha a um 'adestramento', reduzindo a questão ambiental a uma dimensão meramente técnica" (BRÜGGER, 1999, p. 36).

Para vencer os entraves configurados pela dimensão econômica citados acima, as práticas pedagógicas em EA devem seguir viés dialógico e contextual. Visto que "A proposta de uma educação ambiental dialógica ecorelacional parece-nos favorecer a construção de um conhecer integrado, que pode resultar em uma percepção eco-relacional que se corporifica em ecopráxis" (FIGUEIREDO, 2007, p.58).

A Ecopedagogia abarcando as dimensões da confluência entre evolução histórica da realidade econômica e da realidade pedagógica poderá, numa concepção eco-relacional, sinalizar para caminhos mais promissores em sentido de educação, nesse caso específico, de uma ecoformação dialógica para o fortalecimento de práticas educativas mais producentes.

\section{CONSIDERAÇÕES FINAIS}

Faz-se impreterível que a universidade e por extensão a escola básica, debatam possibilidades de uma ação pedagógica concreta e prática, fugindo do tradicional conteudismo. É preciso mais seminários, palestras, congressos que discorram e construam mecanismos alternativos de ensinos pautados no novo perfil de aluno, no novo papel do professor, nas novas tecnologias, em uma nova didática. 
O mundo mudou, os referenciais mudaram, a atual geração tem outros parâmetros de comportamento e ideologias, possui uma gama de ferramentas de interatividades. O aluno tem o tablete! $\mathrm{E}$ o professor? Ainda na era da lousinha mágica. Não podemos mais, enquanto educadores, ficar na mesmice de aulas lineares, com uso exclusivo de pinceis e lousa, usando esqueminhas de aula pré-fabricados que tão somente reproduzem o que trazem os livros didáticos, que em si só são outro problema, visto que os conteúdos não são elencados segundo a realidade de cada região, de cada local.

Em contrapartida, professor e aluno devem juntos construir e reconstruir o conhecimento, checar a aplicabilidade do saber, dialogar abertamente, discente e docente no mesmo patamar, sem pedestais. Essas são algumas das propostas da Ecopedagogia para o ensino ambiental visando uma educação comunitária, como pauta a ética da solidariedade.

O modelo educacional brasileiro não condiz mais com o perfil esperado de cidadão. Observamos um verdadeiro abismo entre os objetivos propostos, os métodos empregados e os resultados obtidos. Contudo, chegamos ao limiar, as possibilidades de sucesso com o tradicional modelo educacional são praticamente nulas. A insatisfação é total, tanto por parte de professores, como de alunos, além dos demais profissionais da educação envolvidos. O sistema educacional deve ser repensado, reinventado, concretizável.

Portanto, é imperativo refletir e traçar novas perspectivas de trabalho pedagógico, remover os entraves, vislumbrar e concretizar novas metodologias, buscar novas orientações didáticas. É necessário promover uma inserção maior da Educação Ambiental, alicerçada na Ecopedagogia, no dia a dia dos sistemas educativos, formais e informais. Assim, avançar-se-á rumo a educação do futuro para satisfazer as demandas da diversidade humana. 


\section{REFERÊNCIA}

BERGMAN, M. Tudo que é sólido desmancha no ar. São Paulo: Companhia das letras, 1990.

BRÜGGER, P. Educação ou adestramento ambiental? 3 ed. Florianópolis: Letras Contemporâneas, 1999.

CAPRA, F. O ponto de mutação: a ciência, a sociedade e a cultura emergente. São Paulo: Cultrix, 1994.

COSTA, M. C. L. Arranjo Familiar e a Vulnerabilidade na Região Metropolitana de Fortaleza. In: COSTA, M. C. L.; DANTAS, E. W. C. (Orgs.) Vulnerabilidade Socioambiental na Região metropolitana de Fortaleza. Fortaleza: Edições UFC, 2009. p. 139-163.

FIGUEIREDO, J. B. Educação ambiental dialógica e representações sociais da água em cultura sertaneja nordestina: uma contribuição à consciência ambiental em Irauçuba - CE (Brasil). 2003. 347 f. (Tese de Doutorado) São Carlos, UFSCAR: 2003.

Educação ambiental dialógica: as contribuições de Paulo

Freire e a cultura sertaneja nordestina. Fortaleza: Edições UFC, 2007.

FREIRE, P. Pedagogia do oprimido. 17 ed. Rio de Janeiro: Paz e Terra, 1987.

GADOTTI, M. Educar para a sustentabilidade: uma contribuição para a década da educação para o desenvolvimento sustentável. São Paulo: Editora e Livraria Instituto Paulo Freire, 2009.

GUERRA, F. S. Percepção ambiental no contexto das representações sociais: um estudo de caso na periferia de Fortaleza-CE. $2017.74 \mathrm{f}$. Monografia (Graduação) - Universidade Federal do Ceará - UFC, Centro de Ciências, Departamento de Geografia, Fortaleza, 2017.

HARVEY, D. A condição pós-moderna: uma pesquisa sobre as origens da mudança cultural. São Paulo: Loyola, 1989.

LOUREIRO, C. F. B. Educação Ambiental e movimentos sociais na construção da cidadania ecológica e planetária. In: (Org. et al) Educação ambiental: repensando o espaço da cidadania. 5. ed. - São Paulo: Cortez, 2011. p. 73-103.

OLIVEIRA, L.; MACHADO, L. M. C. P. Percepção, Cognição, Dimensão Ambiental e Desenvolvimento com Sustentabilidade. In: VITTE, A. C.; GUERRA, A. J. T. (Orgs.) Reflexões sobre a Geografia Física no Brasil. 3 ed. Rio de janeiro: Bertrand Brasil, 2010. cap. 5, p. 129-152.

PRODANOV, C. C.; FREITAS, E. C. Metodologia do trabalho científico [recurso eletrônico]: métodos e técnicas da pesquisa e do trabalho 
acadêmico. 2 ed. Novo Hamburgo: Feevale, 2013. Disponível em: $<$ www.feeavale.br/editora >. Acessado em: 30/03/2017.

RIBEIRO, M. A. Ecologizar: pensando o ambiente humano. 2 ed. Belo Horizonte: Rona, 2000.

ROOS, A. BECKER, E. L. S. Educação ambiental e sustentabilidade. Revista Eletrônica em Gestão, Educação e Tecnologia Ambiental - REGET/UFSM. V. 5, n5, p. 857 - 866, 2012. Disponível em

https://periodicos.ufsm.br/reget/article/viewFile/4259/3035. Acessado em 28/04/2018.

RUSCHEINSKY, A. As rimas da Ecopedagogia: uma perspectiva ambientalista. In: _ (Org.) Educação Ambiental: abordagens múltiplas. Porto Alegre: Artmed, 2002. cap. 4, p. 61-71.

SANTOS, M. Por uma outra globalização: do pensamento único à consciência universal. 16ª Edição, Rio de Janeiro, Record, 2008.

SORRENTINO, M. Desenvolvimento sustentável e participação: algumas reflexões em voz alta. In: LOUREIRO, C. F. B. (Org. et al) Educação ambiental: repensando o espaço da cidadania. - 5. Ed. - São Paulo: Cortez, 2011. p. 1925.

SPOSITO, E. Geografia e Filosofia: contribuição para o ensino do pensamento geográfico. São Paulo: Editora UNESP, 2004.

TORZONI-REIS, M. F. C. Educação ambiental: natureza, razão e história. Campinas: autores associados, 2004. 